\title{
O fardo holandês: escravidão, África e imigrantes nos livros de história da escola primária na Holanda
}

MELISSA F. WEINER*

\section{Resumo}

Há muito, os holandeses se orgulham de sua identidade de povo tolerante, "terra prometida" para imigrantes perseguidos e generosa com fundos de "desenvolvimento" direcionados a outras nações. Esquivam-se, contudo, do papel que desempenharam historicamente no imperialismo, na escravatura e no genocídio colonialistas e consideram os não brancos, tanto na Holanda quanto fora dela, ingratos para com a ajuda de seu país. Esse artigo sintetiza pesquisas anteriores${ }^{1}$ sobre as representações de escravidão, imigração e da África em todos os livros didáticos de história para ensino fundamental na Holanda publicados a partir de 1980, argumentando que estes apresentam metanarrativas eurocêntricas de europeização racial no contexto único da sociedade holandesa. Esses livros perpetuam o esquecimento social, pelos holandeses, da escravidão e do colonialismo científico, justificam intervenções históricas e contemporâneas na África, essencializam e problematizam os imigrantes e suas culturas, destacam a superioridade holandesa e facilitam a ideia de um "fardo holandês", que encontra a Holanda auxiliando, com relutância, minorias dentro e fora de suas fronteiras. Essas descobertas têm implicações importantes para o país e para todas as nações com uma população crescente de imigrantes, pois os discursos e conhecimentos apresentados nos livros didáticos têm afetado gerações sucessivas de estudantes, que formulam políticas locais e nacionais a respeito das minorias, identidades e ideologias raciais.

Palavras-chave: Holanda. Memória social. Livros didáticos. Escravidão. Raça. Imigração.

* College of the Holy Cross, (Estados Unidos).

${ }^{1}$ Para ler o artigo completo abordando a escravidão em livros didáticos holandeses, ver Weiner, 2104a. 
Sociologias, Porto Alegre, ano 17, no 40, set/dez 2015, p. 212-254

\title{
The Dutchman's Burden: Enslavement, Africa and Immigrants in Dutch Primary School History Textbooks ${ }^{* *}$
}

\begin{abstract}
The Dutch have long taken great pride in their identity as tolerant, both as a "promised land" for persecuted immigrants and for generous "development" funds in foreign nations. However, the Dutch eschew their role in historical colonial imperialism, enslavement and genocide and consider non-whites, both in The Netherlands abroad, ungrateful for their nation's aid. This article consolidates previous research addressing depictions of enslavement, immigration, and Africa in all Dutch primary school history textbooks published since 1980 to argue that textbook depictions feature Eurocentric master narratives of racial Europeanization within the unique context of Dutch society. These books perpetuate Dutch social forgetting of slavery and scientific colonialism, justify historic and contemporary interventions in Africa, essentialize and problematize immigrants and their cultures, highlight Dutch superiority, and facilitate a "Dutchman's burden" that finds The Netherlands reluctantly aiding minorities within and outside of their borders. Findings have important implications for both The Netherlands and all nations with increasing immigrant populations as discourses, knowledges presented in textbooks impact generations of students, who shape local and national policy regarding racial minorities, racial identities and ideologies.
\end{abstract}

Keywords: The Netherlands. Education. Curriculum. Textbooks. Race. Europe.

\footnotetext{
** Tradução: Liana V. Fernandes. Revisão técnica Karl Monsma.
} 


\section{Introdução}

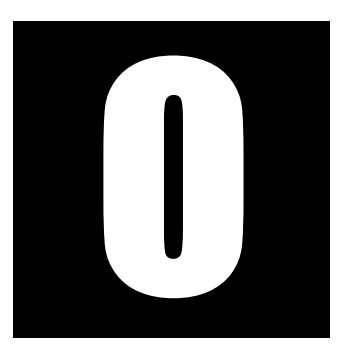

s livros didáticos, elemento essencial nos currículos primário e secundário, desempenham um papel importante ao formar a visão dos estudantes sobre a história de seu país e as concepções sobre grupos raciais e hierarquias raciais e de poder (Giroux, 1997; Giroux; McLaren, 1989; Zimmerman, 2002). Pesquisadores estadunidenses têm demonstrado de forma consistente que os currículos escolares privilegiam a cultura dominante ao obscurecer as raízes históricas da desigualdade racial hoje prevalente e indicar aos alunos quais grupos pertencem ou não à comunidade nacional (Brown; Brown, 2010; Pinar, 1993; Zimmerman, 2002). Textos produzidos a partir de uma perspectiva eurocêntrica em geral excluem as histórias e culturas das minorias e sua opressão por grupos dominantes, enfatizando a superioridade ocidental e, assim, perpetuando ideologias e histórias colonialistas (Araújo; Maeso, 2012b; Willinsky, 1998).

Há hoje, na Holanda, um debate considerável e cada vez mais veemente acerca do lugar dos imigrantes, particularmente os de ascendência afro-holandesa, e das atuais implicações do colonialismo holandês na África, tanto o comércio histórico de escravos africanos, quanto os esforços atuais de ajuda humanitária. Como ocorre em toda Europa, a ascensão de políticos de extrema direita clamando pela expulsão de imigrantes e de suas culturas colide com as demandas de ativistas antirracismo não somente por reconhecimento da presença daqueles na nação e na história nacional, mas também por uma discussão das maneiras em que o colonialismo holandês conforma as atuais desigualdades socioeconômicas. Portanto, o debate sobre quem está ou não incluído nos livros didáticos holandeses reflete outros maiores, a respeito da identidade e a história nacionais. Este artigo sustenta que as abordagens dos temas de África, 
escravidão e imigrantes nos livros escolares holandeses perpetuam antigas ideologias e histórias colonialistas e reificam suas formas contemporâneas. Esses livros trazem, ainda, uma narrativa especificamente holandesa, que caracteriza os não brancos, tanto no passado como no presente, como ingratos para com a intervenção holandesa e seu auxílio aos imigrantes, tratados como eternamente estrangeiros na Holanda e representando o "fardo holandês".

\section{Revisão da Literatura}

Na Europa, o racismo contemporâneo perpetua epistemologias eurocêntricas antigas. Arraigado no encontro colonial, o eurocentrismo reflete uma definição hierárquica binária que coloca a Europa e tudo o que ela produziu como superior ao resto do mundo (Quijano, 2000). Ao designar a Europa como racional, intelectual, moderna e desenvolvida, o resto do mundo fica marcado como primitivo, emocional, tradicional e irracional (Goldberg, 2009; Grosfoguel, 2011; Maldonado-Torres, 2007; Mignolo, 2000; Quijano, 2000). Os discursos eurocêntricos populares e políticos da atualidade seguem valendo-se dessas definições centenárias e de uma relação essencializada com o "outro" menos superior (Frankenberg, 2001), muitas vezes negro. Esses discursos caracterizam povos, culturas e nações como eternamente encravados em passados pré-modernos, precisando do auxílio europeu para desenvolverem-se e modernizarem-se (Nimako, 2011).

Contudo, esses discursos e ideologias explicitamente racistas são frequentemente negados através do neoliberalismo racial e da europeização racial. O neoliberalismo racial, radicado no capitalismo, baseia-se no controle privado de recursos e propõe uma perspectiva individualista do sucesso, desconectada da desigualdade estrutural histórica e contem- 
porânea (Goldberg, 2009). Ele é disseminado, na Europa, por meio da europeização racial, que "enterra viva a história" (Goldberg, 2009) ao despolitizar a presença atual de não brancos no continente, dissociando as desigualdades, hoje vivenciadas por esses, dos séculos de exploração, doutrinas e ideologias colonialistas, e culpando as próprias minorias por suas dificuldades individuais de assimilarem-se socioeconomicamente, assim responsabilizando elas mesmas pelas desigualdades que sofrem (Araújo; Maeso, 2012a; Goldberg, 2009). Séculos de exploração, colonialismo e políticas de subordinação racial não figuram nas explicações sobre as populações heterogêneas na Europa atual ou sobre as desvantagens socioeconômicas dos grupos minoritários em relação aos brancos. Essa narrativa mestra eurocêntrica, hegemônica, que nega as relações de poder, naturaliza os papéis do colonialismo, da escravidão e do racismo no processo de desenvolvimento da Europa como centro moderno da economia capitalista global, sem deixar espaço suficiente às vozes dos oprimidos para superar a exclusão da raça e do racismo dos discursos de nacionalidade, democracia e cidadania (Araújo; Maeso, 2012a; Grosfoguel, 2011). Na Holanda, uma forma única de europeização racial se realiza por meio do esquecimento social e da distorção, marginalização ou banalização da escravidão e do colonialismo no Caribe e na África, da importância dessas regiões para o crescimento da nação e de sua relevância para a presença de imigrantes em solo holandês (Nimako; Small, 2012).

Segundo muitos, "raça" não existe na Holanda (Essed; Hoving, 2014; Essed; Nimako, 2006; Hondius, 2014; Dijk, 1993). Como "raça" e "racismo" são considerados tabus e há prevalência de antirracialismo, formuladores de políticas e acadêmicos preferem o termo "etnicidade", que evoca noções de cultura, mas não dá conta das relações hierárquicas de poder e dos julgamentos de valor centrais às identidades raciais e aos processos de racialização incrustados na sociedade holandesa (Essed; 
Nimako, 2006; Essed, Trienekens, 2008; Weiner, 2014b). Essa preferência por "etnicidade" sobre "raça" tanto perpetua a europeização racial, negando a existência de raças, como encobre a realidade do racismo institucional e cotidiano vivenciada pelos não brancos (Essed; Nimako, 2006; Essed ; Trienekens, 2008; Nimako, 2012).

A narrativa nacional holandesa transmite a ideia de uma generosidade excessiva para com povos que não valorizam a ajuda recebida, reproduzindo assim a histórica noção do "fardo do homem branco", segundo a qual cabia aos brancos ocidentais a responsabilidade de conduzir os povos não brancos à era moderna, pois Ihes faltavam civilização, tecnologia e modernidade. Não brancos são considerados ingratos para com a ajuda recebida, tanto nos seus próprios países como, especialmente, na Holanda, onde, depois da imigração, podem aproveitar as generosas políticas de assistência social, de forma que os holandeses brancos se tornaram vítimas de sua própria generosidade (Essed; $\mathrm{Ni}$ mako, 2006; Ghorashi, 2014). De maneira semelhante, esses discursos ignoram a exploração histórica e contemporânea desses grupos pelos holandeses, tanto dentro como fora da Holanda.

Histórias e representações em livros didáticos

Debates acerca de livros didáticos são, essencialmente, debates sobre identidade nacional e pertencimento (Apple; Christian-Smith, 1991; Fitzgerald, 1979; Giroux, 1997; Giroux; McLaren, 1989; Zimmerman, 2002). Currículos que privilegiam a cultura dominante e excluem minorias, omitindo sua opressão pelo grupo preponderante não só encobrem as raízes históricas da desigualdade contemporânea como também indicam aos alunos quais grupos pertencem à comunidade nacional (Brown; Brown, 2010; Pinar, 1993; Tyack, 1999; Zimmerman, 2002). Nos EUA, há séculos; grupos de não brancos, trabalhadores e 
mulheres têm exigido que o currículo reflita corretamente suas contribuições para a construção da nação (Binder, 2002; Moreau, 2003; Weiner, 2010; Zimmerman, 2002).

Esses debates seguem sendo controversos, e muitas vezes mudam de rumo, dependendo do poder político e do peso demográfico de determinados grupos. Por exemplo, a crescente população de latinos nos EUA preconiza cada vez mais a inclusão das contribuições de latinos para a história do país, especialmente no sudoeste. De forma similar, a reação contra os livros escolares mais inclusivos persiste. Por exemplo, uma decisão recente, no estado do Texas, minimiza as discussões da escravidão e das leis segregacionistas de Jim Crow nos livros escolares desse estado, e uma lei do estado do Arizona (HB2281) proíbe o ensino de história dos americanos de origem mexicana aos estudantes de um estado cujo território já foi parte do México. Debates similares ocorrem na Holanda e em outros países europeus com populações crescentes e cada vez mais mobilizadas de não brancos. Na subseção a seguir, são descritas as histórias documentadas da escravidão e da intervenção holandesa na África, bem como a dos imigrantes na Holanda contemporânea. Apresentam-se também pesquisas recentes sobre como esses tópicos são apresentados em livros didáticos de história, tanto na Holanda como em outros países.

A escravização e o envolvimento dos holandeses na África

A Holanda desempenhou um papel importante no comércio de escravos e no colonialismo na África. Estendendo-se por três séculos, o empreendimento escravagista holandês gerou milhões em lucros e consolidou, tanto nas colônias quanto na metrópole, discursos de racialização dos africanos, justificando a sua escravização. Africanos escravizados e seus descendentes cultivavam, colhiam e processavam café, cana de açúcar, cacau e algodão nas Antilhas holandesas (Aruba, Curaçau, Bonaire, 
São Martinho, Santo Eustáquio e Sabá) e no Suriname (Nimako; Willemsen, 2011). A renda da exploração do trabalho nessas colônias, e também na Indonésia, construiu a economia holandesa no sistema global, enquanto solapava a infraestrutura das colônias (Horton; Kardux, 2005; Nimako; Willemsen, 2011). O abolicionismo era praticamente ausente na Holanda, e corsários holandeses (leia-se piratas) comercializavam homens, mulheres e crianças escravizadas mesmo após a proibição do tráfico em 1814 (Drescher, 1994; Nimako; Willemsen, 2011). A Holanda aboliu legalmente a escravidão em 1863, mas exigiu um período de "aprendizagem" de dez anos, que os holandeses brancos afirmavam ser necessário para que os escravizados aprendessem o significado e as responsabilidades da liberdade (Drescher, 1994; Nimako; Willemsen, 2011). O governo holandês então compensava financeiramente senhores de escravos por sua perda de "propriedade".

$\mathrm{Na}$ África, além de sua base escravista na fortaleza de Elmina, na costa oeste africana, os holandeses estabeleceram uma colônia na região que hoje corresponde à África do Sul para obter suprimentos durantes as travessias entre a Holanda e sua colônia na Indonésia (ver Fredrickson, 1981). Colonos holandeses referiam-se aos povos africanos como "selvagens desprezíveis", "as pessoas mais preguiçosas sob o sol", "que ocupam a posição mais baixa na escala evolutiva" (Fredrickson, 1981, pp. 34, 56, 196). Esses sentimentos justificavam a apropriação das terras dos Xhosas e dos Zulus, o genocídio quando a população resistia e, posteriormente, o estabelecimento de uma "democracia da raça superior" (herrenvolk) para manter a segregação racial (apartheid), antes de sua instituição oficial em 1948.

Atualmente, os holandeses mantêm laços comerciais e de desenvolvimento com a África e orgulham-se de seu envolvimento em organizações não governamentais (ONGs). Há muito, mantêm a reputação de 
doadores generosos (Hoebink, 1999), contudo, o financiamento de projetos pela Holanda baseia-se geralmente na probabilidade de êxito para satisfazer os doadores, e não na gravidade dos problemas que propõem abordar, ou exige a aquisição de produtos e serviços holandeses com os auxílios (Bebbington, 2005; Bijl, 2012; Derksen; Verhallen, 2008).

Apesar de seu papel proeminente na história mundial da escravidão, os holandeses continuam exibindo posturas contraditórias a respeito de sua cumplicidade com o sequestro, escravização e exploração de africanos e com o apartheid na África do Sul e dificilmente reconhecem as conexões entre a escravidão e as desigualdades vivenciadas pelos afro-holandeses nos Países Baixos hoje (Nimako; Small 2012; Nimako; Willemsen, 2011). Alguns pesquisadores descrevem essa prática institucionalizada do esquecimento da escravidão na narrativa nacional holandesa como um "ato voluntário de esquecimento" (Horton; Kardux, 2005: 42; Nimako; Small 2012). A historiografia holandesa evidencia tendências parecidas, valendo-se do colonialismo científico para retratar "o colonialismo como uma forma normal de relações", e não como "um sistema de exploração e opressão" (Hira, 2012: 53). Só recentemente, os pesquisadores críticos começaram a abordar o papel central da escravização na Era de Ouro dos Países Baixos, colocando em questão a metanarrativa do envolvimento limitado da Holanda na escravização e no comércio de africanos (Hira, 2012; Hondius, 2011; Horton; Kardux, 2005; Nimako; Small 2012; Nimako; Willemsen, 2011; Zunder, 2010).

Embora alguns defendam a importância da inclusão de análises críticas da escravidão como tópico obrigatório nas matérias de história europeia e nos exames em todos os níveis da educação (por exemplo, Cole, 2004; Deveau, 2001; Lyndon, 2006), ainda é escassa a literatura acadêmica que analisa as representações da escravidão nos livros didáticos europeus. A que existe constata que textos educacionais aplicam epistemologias eurocêntricas para glorificar os projetos colonialistas eu- 
ropeus, sem abordar o impacto da escravização nas vidas de milhões de africanos escravizados ou das famílias e comunidades que ficaram para trás, retratando a escravidão primariamente como um fenômeno americano, ou simplesmente omitindo-a (Araújo; Maeso, 2012a; Broeck, 2003; Cole, 2004; Deveau, 2001). Essa omissão é sintomática da europeização racial, silenciando o papel da escravidão no estabelecimento da hegemonia social, política e econômica europeia (e de determinados países europeus) durante o último meio milênio (Goldberg, 2009; Grosfoguel 2011; Wallerstein 1980, 1974).

Como na Europa, representações da escravidão em livros didáticos dos Estados Unidos apresentam uma metanarrativa de dominação branca eurocêntrica que "deixa de tratar de questões fundamentais como o propósito, as causas e as consequências de eventos e sistemas como a escravidão" (Swartz, 1992, p. 343). Esses textos ignoram o racismo institucional e retratam a escravização num tom distanciado e perfunctório que "oculta o papel opressivo dos que perpetuaram a escravidão" (Foster, 1999, p. 269). Isso higieniza a escravidão, apresentando-a como algo neutro, em vez de ser central para o desenvolvimento da economia capitalista mundial, estreitamente vinculada com a ideologia racista e a acumulação de recursos (Magubane, 2004; Ogden et al., 2008; Sivanandan, 1982).

Ao apresentar a escravidão sob essa perspectiva branca, com apenas alguns senhores "maus", a maioria dos livros "ignora, solapa, ou deturpa os vínculos institucionais/estruturais maiores que apoiaram (por ação e/ou omissão) e, sobretudo, beneficiaram-se da sua adoção" (Brown; Brown, 2010, p. 45). Ao incluir, de modo indulgente, as vozes dos senhores de escravos e não as dos escravizados, os livros didáticos reproduzem imagens estereotipadas desses últimos como figuras de físico forte, delinquentes, de aspecto igual, que inspiram medo aos brancos, e gostam de música, dança e histórias; adequados à exploração, e desprovidos de inteligência, 
cultura, história e agência (Brown; Brown, 2010; Foster, 1999; Gordy; Pritchard, 1995; Swartz, 1992).

Representações da África em livros didáticos contemporâneos descrevem essencialmente o continente principalmente em relação à Europa, à civilização, à dominação e ao poder global europeus (Frijhoff, 2010; Marino, 2011; Sefa Dei, 2010). Representações históricas da África antes da chegada dos europeus raramente aparecem e, quando existem, destacam culturas e uma humanidade "primitivas" (Marmer et al., 2010; Dijk, 1993). A história africana inicia com o contato europeu, a África sendo concebida como um local de descoberta (Alvermann; Commeyras, 1994; Marmer et al., 2010; Wilson, 1995). Os livros-texto raramente abordam "escravidão, conquista violenta ou explorações neocoloniais das regiões do Terceiro Mundo", em vez disso, perpetuam o mito de que os europeus levaram (e continuam levando) a "civilização aos bárbaros em países de Terceiro Mundo" (Marmer et al., 2010; Dijk, 1993, p. 204). Análises da África contemporânea continuam esses discursos ao destacar implícita e explicitamente a "alteridade" dos africanos através de representações suas como atrasados, selvagens, preguiçosos, violentos, primitivos, exóticos, nus, subdesenvolvidos, delinquentes e drogados (Marmer et al., 2010; Manzo, 2006; Myers, 2001; Popke, 2001; Dijk, 1993). Livros didáticos holandeses reproduzem essas opiniões enfatizando o papel político, econômico e cultural dos holandeses no mundo, particularmente sua superioridade e tutela em relação a questões sociais (Frijhoff, 2010).

As lutas por independência, em lugar de referirem-se a ideologias anticoloniais e à resistência gerada e desenvolvida sob condições de opressão racial e estrangeira, são mostradas como irrupções violentas de "tribos selvagens e fanáticas" que vitimam os brancos (Dijk, 1993). As ideologias de independência africanas são atribuídas ao pensamento liberal ocidental, e não à rejeição dos africanos a séculos de opressão colonialista (Alvermann; Commeyras, 1994). Os livros didáticos representam as na- 
ções africanas independentes como politicamente retrógradas, lideradas por ditadores e perpetuamente precisando da "nossa" democracia, de intervenções e de auxílios ocidentais (Downing, 1980).

Imigrantes na Holanda

Antilhanos, surinameses, turcos e marroquinos representam atualmente os quatro maiores grupos de minorias não ocidentais na Holanda, a maioria dos quais reside nas suas quatro maiores cidades, Amsterdã, Roterdã, Haia e Utrecht. Embora tenha sido por muito tempo uma nação receptiva a imigrantes, essa "nova" imigração de turcos e marroquinos, iniciada na década de 1960, e de surinameses e antilhanos, na década de 1970, gerou considerável xenofobia entre a população holandesa, estimulada e exacerbada por figuras políticas de direita. Comparando-se esses grupos com os holandeses brancos nativos, revela-se uma hierarquia racial, com os antigos súditos coloniais situados entre os holandeses, do topo, e os turcos e marroquinos da base. Tal hierarquia resulta no acesso correspondente, ou na falta dele, aos recursos sociais e oportunidades.

Competindo com o holandês nativo por vagas escassas, esses grupos de imigrantes, com níveis de escolaridade inferiores aos de holandeses brancos, estão cada vez mais em desvantagem na economia de serviços da Holanda e têm altas taxas de desemprego em comparação aos nativos brancos com qualificações escolares semelhantes (Snel et al., 2005; Ours; Veenman, 2003; Vasta, 2007). Alegações comuns de que a população imigrante já estabelecida tem estimulado a "imigração ilegal" e estereótipos desses grupos como "violentos", "desonestos", "intrusivos", "desleixados", "queixosos", faltando respeito às leis e inassimiláveis, resultam na discriminação manifesta nas escolas, nos espaços públicos e no mercado de trabalho (Engbersen; Leun, 2001; Heath et al., 2008; Sniderman; Haagendoorn, 2009). 
O uso de allochtoon (alóctone) para descrever holandeses não brancos e autochtoon (autóctone) para holandeses nativos brancos reflete o maior valor atribuído a essa última identidade (Essed; Trienekens, 2008). A criação e vigilância dessa fronteira inibe a aceitação social de descendentes de imigrantes não europeus que compartilham natividade, língua, cultura e cidadania com "holandeses nativos". Não há uma língua disponível aos migrantes para reivindicar identidades múltiplas (como ganês-holandês, por exemplo) (Ghorashi, 2009).

A escassa pesquisa sobre representações dos imigrantes nos livros didáticos holandeses revela um tratamento racista e essencializante, que nega a opressão e o poder históricos e atuais dos brancos e das nações ocidentais (Dijk, 1993). Livros que abordam a imigração traçam fronteiras claras entre "nós", os "verdadeiros" habitantes nativos do país, e "eles", através de uma postura discursiva que desenha os cidadãos e a nacionalidade holandeses como superiores às nações e culturas de imigrantes (Foster, 1999; Loewen, 2007; Dijk, 1993). Como nos EUA, os livros didáticos holandeses "estão plenos de representações estereotipadas, quando não explicitamente eurocêntricas e racistas, de minorias e de povos do Terceiro Mundo, e continuam ignorando por completo os grupos minoritários e suas culturas" (Dijk, 1993, p. 200; Foster, 1999; Fitzgerald, 1979; Loewen, 2007).

Os textos falam sobre imigrantes utilizando-se de categorias gerais (ou seja, trabalhadores convidados, em vez de turcos e marroquinos), realçam suas culturas "estranhas" e "atrasadas", a criminalidade, a misoginia, hábitos, comida, roupas, música e idiomas, e sugerem uma presença "ilegal" de imigrantes, uma vez que eles "transbordam", "invadem" e "inundam" a Holanda (Mok, 1990). Os livros presumem que as diferenças culturais impedem a assimilação dos imigrantes pelo estado holandês benevolente e tolerante, que fornece assistência financeira generosa (ibid.). Combinadas, essas narrativas facilitam a empatia com o branco nativo 
holandês e justificam a xenofobia, ao mesmo tempo dificultando a integração dos imigrantes na sociedade holandesa. As recentes alterações feitas no currículo de história no país desenfatizaram as diferenças culturais, ou tornaram-nas problemas a serem enfrentados, em vez de realidades a serem acolhidas e/ou celebradas (Sunier, 2009).

\section{Coleta de dados e metodologia}

Para avaliar representações da escravidão, dos imigrantes, e da África examinei as versões mais recentes de todos os livros-texto, livros de exercícios e cadernos de atividades de história para o ensino primário na Holanda publicados desde 1980 ( N=203), recorrendo, principalmente, às técnicas de análise utilizadas por Araújo e Maeso (2012a), Swartz (1992), e Pescosolido et al. (1997). Todos os livros examinados, os quais podem ser encontrados na Biblioteca Real holandesa, em Haia, estão escritos em holandês e todas as traduções são minhas. Cada livro foi lido atentamente em busca de discussões e imagens da escravidão, da África e de imigrantes. As páginas que abordam esses fenômenos foram fotografadas no local e, em seguida, digitadas e importadas, juntamente com fotografias das ilustrações, ao programa Atlas.ti, para análise.

Estratégias de análise do discurso e de conteúdo (ver Dijk, 1993), combinadas com categorias de codificação indutivas e dedutivas (Fereday; Muir-Cochrane, 2006), permitiram a avaliação holística das representações da escravidão, da África e de imigrantes nesses textos. A codificação dedutiva e indutiva facilitou a geração de categorias de codificação baseadas em estudos que tratam desses fenômenos e a criação de novas categorias à medida que estas surgiam. A análise do discurso permitiu a percepção da perspectiva a partir da qual esses tópicos são apresentados e das lições que os alunos aprendem em relação à história e à sociedade holandesas. 
Sociologias, Porto Alegre, ano 17, no 40, set/dez 2015, p. 212-254

Tabela 1. Todas as variáveis examinadas nos livros didáticos

\begin{tabular}{|c|c|c|}
\hline Escravidão & África & Imigrantes \\
\hline Escravidão & Primitiva & Imigração \\
\hline Escravidão holandesa & Violenta & Grupos de imigrantes \\
\hline No sumário & Crime & Indonésios \\
\hline $\begin{array}{l}\text { Justificativa - } \\
\text { mão-de-obra }\end{array}$ & Pouca educação & Surinameses \\
\hline Justificativa - África & Doença & Antilhanos \\
\hline Justificativa - lucro & Pobreza & Turcos \\
\hline $\begin{array}{l}\text { Responsabilidade } \\
\text { holandesa }\end{array}$ & Colônias & Marroquinos \\
\hline Voz passiva & Fonte de produtos & Italianos \\
\hline $\begin{array}{l}\text { Resistência nas } \\
\text { plantações }\end{array}$ & Refugiados & Espanhóis \\
\hline Quilombolas & Diferenças culturais & Judeus \\
\hline Comércio & Natureza & Africanos \\
\hline Emoções de escravos & Outros estereótipos & Asiáticos \\
\hline $\begin{array}{l}\text { Perspectiva } \\
\text { dos brancos }\end{array}$ & Qualquer estereótipo & lugoslavos \\
\hline Outros países & Pré-Europa & Sul-americanos \\
\hline Maus-tratos & Descoberta/Exploração & Outros europeus \\
\hline Escravos NA África & África do Sul (AS) & $\begin{array}{l}\text { Trabalhadores } \\
\text { convidados }\end{array}$ \\
\hline $\begin{array}{l}\text { Escravos africanos } \\
\text { são melhores }\end{array}$ & Africa do Sul holandesa & Refugiados \\
\hline Não tão ruim & Elmina/Guiné & Motivos para deixar o país \\
\hline $\begin{array}{l}\text { Canções/estórias/ } \\
\text { cultura de escravos }\end{array}$ & Escravidão & Religião \\
\hline \multirow[t]{5}{*}{ Estereótipos negativos } & Desenvolvimento & Trabalho \\
\hline & Protesto & Educação \\
\hline & Independência & Crenças políticas \\
\hline & Vozes africanas & Violência \\
\hline & ONGs & Futuro melhor \\
\hline
\end{tabular}

continua... 


\begin{tabular}{|c|c|c|c|}
\hline Escravidão & África & Imigrantes & \\
\hline & Crianças & & Pobreza \\
\hline & Direitos & Características & \\
\hline & Mapas & & $\begin{array}{l}\text { Diferenças } \\
\text { culturais }\end{array}$ \\
\hline & Exploração & & Islã \\
\hline & Produtos & & Pobreza \\
\hline & Colônias & & Urbanos \\
\hline & Pobreza & Tolerância? & \\
\hline & Violência & & Multiculturalismo \\
\hline & Refugiados & & Colorido \\
\hline & Escravidão & & $\mathrm{M} / \mathrm{C}+$ Colorido \\
\hline & Intocada & & Allochtoon \\
\hline & Ausência & & $\begin{array}{l}\text { Discriminação } \\
\text { nos PB }\end{array}$ \\
\hline & Nações individuais & & Benevolência \\
\hline & África do Sul & & Problemas \\
\hline & Separada & & Racismo \\
\hline & Natureza & Números & \\
\hline
\end{tabular}

\section{Achados}

\section{A África na história}

Embora mostrada em 95 (46,8\%) dos 203 livros didáticos analisados, a África está ausente da maioria deles. Em apenas 7,4\% deles há vozes africanas com relatos de sua captura para a escravidão, descrição de sua cultura primitiva, ou testemunho das suas vidas em condições de pobreza ou como crianças-soldado (Panday et al., 2000, p. 43, 48; Reenen, 1998, p. 65, Wagenaar et al. 2004, p. 48). Os livros escolares retratam a África 
principalmente como um local de descoberta, exploração ou consumo para brancos europeus, os produtos variando de amendoins a pessoas (ou seja, africanos escravizados). Quase metade, 49,5\%, retrata a África como um local de descoberta, e $41,1 \%$ refere-se ao continente como uma fonte de produtos. Nenhum traz as percepções dos africanos sobre o colonialismo ou seu desejo de independência, tampouco leva aos estudantes a voz de pelo menos um líder africano. A maioria conta a história da África apenas a partir do contato com os europeus, com apenas 11,6\% dos livros citando o continente antes da chegada desses últimos. Um único descreve uma civilização africana sofisticada pré-contato europeu. Ignorando explicitamente os povos africanos, um dos livros diz: "No século 19, o interior da África foi descoberto" (Brug, 1991, p. 50).

Tabela 2. Variáveis relacionadas à África

$\%$

Características

Primitiva

28.42

Violenta

16.84

Crime

3.16

Pouca educação

5.26

Doença

10.52

Pobreza

25.26

Colônias

27.27

Fonte de produtos

41.11

Refugiados

16.84

Natureza

10.53

Outros estereótipos

5.26

continua... 
continuação

\begin{tabular}{ll}
\hline & $\%$ \\
\hline Pré-Europa & 11.58 \\
África do Sul & 37.74 \\
& 9.47 \\
Elimina/Guiné & 13.68 \\
Escravidão & 30.52 \\
Descoberta/Exploração & 49.47 \\
Protesto & 4.21 \\
Desenvolvimento & 3.16 \\
Independência & 14.74 \\
ONGs & 13.68 \\
Crianças & 18.95 \\
Direitos & 6.32 \\
Diferenças culturais & 6.32 \\
Imagem & 31.58 \\
Mapa mundial & 71.58 \\
Vozes africanas & 7.37 \\
Qualquer estereótipo & 52.63 \\
\hline
\end{tabular}

\section{Escravidão}

Dos 203 livros didáticos e cadernos de atividades publicados desde 1980, 49 (33 livros-texto, 15 cadernos de atividades e um manual do professor) mencionam a escravização de africanos e 40 (19,7\%) abordam a escravização ou o comércio holandês de africanos escravizados. Nenhum dos livros inclui raça ou racismo em suas abordagens da escravidão. Os livros só discutem o comércio de africanos escravizados no contexto da 
Companhia Holandesa das Índias Ocidentais (WIC). Não mencionam a Middlebury Commerce Company (que precedeu a WIC) ou os muitos mercadores independentes que transportavam os africanos antes e após a abolição do comércio em 1814 (Nimako; Willemsen, 2011). Não há menção à presença de africanos escravizados na Holanda.

As representações dos escravos africanos tanto desumanizam os negros, com mais de dois terços dos livros $(67,35 \%)$ omitindo qualquer referência humanizante (famílias, cultura, na forma de canções, histórias, línguas ou nomes, ou emoções), como reproduzem estereótipos dos africanos (30,6\%). Nesse último aspecto, alguns livros descrevem os africanos ou como trabalhadores "fortes" e melhores do que nativos sul-americanos e antilhanos (12,2\% dos livros), que dançavam nas plantações ou durante a Passagem do $\mathrm{Meio}^{2}$, ou como violentos (Brenninkmeyer et al., 1995; De Bruin, 2003b; Fenger; Siemensma, 2005;. Goris et al., 2008; Vlis, 1986; Duinen, 1983).

\footnotetext{
${ }^{2}$ Referência ao comércio triangular através do Atlântico, em que a Europa enviava produtos manufaturados para a África, trocando-os por escravos que eram, então trocados no Novo Mundo por matérias primas para suprir a Europa. A "Passagem do Meio" era considerada um momento intermédio para aqueles que estavam sendo traficados da África para a América, A proximidade e a divisão dos grupos determinadas pela tripulação dos navios criava laços de afinidade entre os cativos. [Nota da Tradutora. Ver: https://en.wikipedia.org/wiki/Middle_Passage]
} 
Tabela 3. Variáveis relacionadas à escravidão

\begin{tabular}{ll}
\hline & $\%$ \\
\hline Justificativa - mão-de-obra & 28.57 \\
Justificativa - África & 16.33 \\
Justificativa - lucro & 24.49 \\
Justificativa - mão-de-obra e lucro & 40.8 \\
Responsabilidade holandesa & 34.69 \\
Voz passiva & 63.27 \\
Resistência nas plantações & 20.41 \\
Quilombolas & 36.73 \\
Comércio & 48.98 \\
Emoções de escravos & 20.41 \\
Escravos com famílias & 12.24 \\
Outros países & 30.61 \\
Maus-tratos & 61.22 \\
Escravos NA África & 44.9 \\
Escravos africanos são melhores & 12.24 \\
Não tão ruim & 10.2 \\
Canções/estórias/cultura de escravos & 14.29 \\
Humanidade dos negros & 32.65 \\
Estereótipos negativos & 30.61 \\
Estereótipos neg. + Escravos na África & 57.14 \\
\hline
\end{tabular}


Quase a metade dos livros (49\%) explica o comércio escravagista no contexto dos esforços coloniais para gerar riqueza para a metrópole. Para acumular riquezas, um livro explica, os holandeses "foram primeiro para a costa oeste da África. Lá, encontraram um comércio muito melhor: escravos!" (Panday et al., 2000, p 45). A maioria dos livros tenta descrever o tráfico holandês no contexto de um empreendimento comercial global, ao mesmo tempo minimizando o envolvimento da Holanda. No entanto, um livro destaca o talento holandês para o comércio, um traço do qual os holandeses sempre se orgulharam, revelando que: "Os holandeses também eram 'bons' no comércio de escravos" (Reenen, 1998, p. 323). Muitos livros apartam os holandeses dessa prática, afirmando ser obra da WIC, formada por mercadores, e não do povo ou do governo da Holanda. No total, mais de $40 \%$ dos livros justificam o comércio de africanos escravizados pela necessidade de mão-de-obra ou pelo lucro. Algumas explicações típicas para a escravidão afirmam que, ao colonizar o Suriname e as Antilhas Holandesas, "precisava-se de escravos para o trabalho nas plantações" (De Bruin, 2003a, p. 60), pois "havia muito poucos trabalhadores. Então, Espanha, Portugal e a WIC trouxeram trabaIhadores da África" (Janssen et al., 2010, p. 6). Também linguisticamente a maioria dos livros distancia os holandeses dessa exploração, mudando da voz ativa, usada para descrever o comércio de escravos africanos, para a passiva quando se aborda a escravidão nas plantações. Em um dos livros lê-se, por exemplo, "havia escravos negros da África que trabalhariam nas plantações" (Boivin, Torreman, 1995, p. 30).

Quase metade dos livros $(44,9 \%)$ reduz os africanos a escravos, afirmando que os mercadores capturavam "escravos da África" [slaven uit Afrika], ao invés de dizer que compravam africanos cativos e os escravizavam. Em 16,3\% dos livros didáticos, a escravidão é justificada como já existindo na África, de modo a naturalizar a utilidade essencial dos 
africanos como trabalhadores, para o lucro dos brancos, especialmente ao agregarem-se, em 12,2\% dos livros-texto, afirmações de que os africanos eram escravos melhores que os nativos antilhanos e sul-americanos.

Se as vozes e ideologias contemporâneas dos africanos escravizados raramente estão presentes nos livros didáticos, os estudantes encontram muito mais as dos brancos senhores de escravos. Há referências reiteradas nos livros-texto ao fato de os brancos perceberem e tratarem os africanos escravizados como "animais" ou "bichos de estimação" (de Bruin, 2001, 2003b), enquanto os cadernos de atividades que os acompanham perguntam aos alunos, de diferentes formas, "quais pessoas achavam muito natural a escravidão?" (Visser-van de Brink et al., 2006, p. 42; de Bruin, 2003b, 2001). Evidenciando a perspectiva dos brancos, um livro explica que "a vida do escravo negro não era tão difícil aos olhos dos brancos" (Wagenaar et al., 2004, p. 52). Outro livro resume o ponto de vista de milhões de holandeses brancos ao longo dos séculos, afirmando: "Por mais de 200 anos, os holandeses consideraram perfeitamente normal a escravidão" (Goris et al., 2008, p. 37). Abordando de forma indulgente as "dificuldades" encontradas por brancos mercadores e senhores de escravos, os livros descrevem os perigos enfrentados por esses, levando muitos à morte por doenças e naufrágios durante a Passagem do Meio, e afirmam que "a vida não foi fácil para os brancos" nas plantações (Brenninkmeyer et al., 1995, p. 21;. Buijtendijk et al., 1986; de Bruin, 2003a; Wagenaar et al., 2004).

Menos da metade (41\%) dos livros menciona a resistência dos africanos escravizados. Os que o fazem, é quase sempre aquela na forma de fugas ou revoltas nas plantações, mas raramente abordando as formas mais sutis, dissimuladas, de resistência. Quando mencionada, a resistência surge como reação a maus tratos, e não como uma reação contra a economia racista globalizada, baseada no trabalho de homens, mulheres 
e crianças escravizados. Presentes em 36,7\% dos livros, os quilombolas, cativos africanos "que conseguiram construir uma existência independente nas florestas" (de Bruin, 2003b, p. 18) e que seriam severamente punidos se capturados (Visser-van de Brink et al., 2006, p. 71). A maioria desses livros descreve quilombolas que aterrorizam os brancos, ou os representa como perigosos ou ameaçadores (isto é, vestindo só tanga, segurando uma lança). A representação de homens (nunca mulheres) escravizados ou quilombolas desafiando a escravidão de forma violenta permite transformar os brancos em vítimas de "homens negros raivosos". Essas representações reproduzem o ponto de vista dos senhores de escravos, que provavelmente viam a resistência como egoísta, e não como uma forma de revolta contra o sistema escravista.

Essa visão branca da resistência é reforçada por descrições dos castigos como motivados por negligência no trabalho (mas nunca como forma de dominação, nem como cruéis e abusivos), acompanhadas de imagens de escravos e escravas bem-vestidas, sorrindo ao cantar e dançar. Frases típicas usando a voz passiva incluem "os escravos eram maltratados" (Panday et al., 2000, p. 47) ou "nas plantações de açúcar, a vida era insuportável" (de Bruin, 2003a, p. 58), faltando, assim, a referência a quem maltratava os africanos escravizados e tornava insuportável suas vidas. Cerca de um décimo dos livros descreve esse tratamento e as vidas dos escravos africanos nas plantações como "não tão ruins" (Goris et al., 2008, p. 38), especialmente para aqueles que trabalhavam nas casas e não nos campos, pois "alguns donos de escravos os tratavam bem" (Visser-van de Brink et al. 2006, p. 71) e muitos dos escravizados não precisavam trabalhar aos domingos (Goris et al., 2008, p. 27). Tais discursos justificam a violência holandesa contra os africanos e, em muitos casos, a legitimam, culpando as próprias vítimas por ela. 


\section{A África hoje}

A imagem da África nos livros didáticos nunca evoluiu significativamente além da ideia do continente como berço primevo da humanidade. A maioria deles retrata os africanos como primitivos, violentos ou refugiados pobres que sempre serão, em essência, culturalmente diferentes; e a África como um continente em que abundam doença e crime, e onde a educação é rara. Cerca de um décimo deles fala da natureza, velha representação da África como terra selvagem, indômita, em contraste com uma Europa racional, organizada e industrial. Os mapas-múndi encontrados na maioria $(71,6 \%)$ dos livros que falam da África, colocam o continente como uma escala para europeus a caminho de outro lugar, um lugar onde adquirem produtos, um local de colonização (em que as diferentes cores dos mapas sinalizam os países colonizadores), ou como lugar sem civilização. Um quarto $(25,3 \%)$ dos livros corta ou distorce os mapas africanos, enquanto quase um terço $(32,4 \%)$ apresenta a África como um local de ausências, sem religião, riquezas ou paz. 
Tabela 4. Variáveis caracterizando a África em mapas-múndi

\begin{tabular}{ll}
\hline & $\%$ \\
\hline Exploração & 34.4 \\
Produtos & 17.7 \\
Colônias & 16.7 \\
Pobreza & 8.3 \\
Violência & 2.1 \\
Refugiados & 3.1 \\
Escravidão & 20.8 \\
Intocada & 17.7 \\
Ausência & 22.9 \\
Nações individuais & 10.4 \\
Detalhes & 4.2 \\
África do Sul & 22.9 \\
Separada & 16.7 \\
Natureza & 5.2 \\
\hline
\end{tabular}

Há mais livros (27,3\%) que descrevem a África como lugar de colonização europeia do que aqueles que descrevem as nações africanas $(14,7 \%)$. Falta agência a essas últimas, que são tratadas como parte da história das conquistas europeias. "Os europeus consideravam os novos países como sua propriedade" (Venema, 1985, p. 59). "Muitos países europeus tinham, entre 1500 e 1900, conquistado muitas áreas possíveis na África e na Ásia. Esses lugares conquistados foram chamados de colônias" (Vorst; Weber, 2004, p. 82). Embora mencionem-se as colônias, o colonialismo não é tocado. Não há discussão sobre a percepção do colonialismo pelos africanos, da sua exploração, dos lucros maciços gerados para as nações e corporações europeias pelo colonialismo, da destruição sistemática de famílias, comunidades, culturas tribais ou economias. 
A independência africana, citada em 14,7\% dos livros, aparece subitamente, sem discussão de por que "muitos países se tornaram independentes após a Segunda Guerra Mundial" (Panday; Kouwenberg, 1997, p. 61). Os livros raramente informam de quais nações europeias os países africanos se tornaram independentes. Tampouco explicam como a independência se concretizou, por que tantos países, em tão pouco tempo, a conquistaram, quem a almejava, o que significava não ser independente para os africanos ou as organizações de resistência, e o pensamento nacionalista antes da independência. Os livros didáticos representam nações africanas independentes como pobres, violentas, e lideradas por ditadores (Baaijens; Klinken, 1996; Boivin; Torreman, 1995).

Quase todos os livros misturam África com Ásia e América do Sul ao discutirem desenvolvimento, essencializando o Sul Global. Uma afirmação recorrente em diversos textos é: "a maioria dos países da África, Ásia e América do Sul é muito pobre" (Vorst \& Weeber, 2004, p. 106). Associando explicitamente pobreza e desenvolvimento, um livro define, inicialmente, país em desenvolvimento como "um país pobre que recebe ajuda de países ricos", e então afirma: "muitos países em desenvolvimento encontram-se na África e na Ásia" (Panday; Kouwenberg, 2001, p. 61). Essas descrições essencializam continentes inteiros, ignorando diferenças políticas, econômicas e sócio-históricas entre as nações.

$\mathrm{Na}$ maioria dos livros didáticos, o envolvimento holandês com a África está limitado à ajuda contemporânea. Embora mais de um terço $(37,7 \%)$ deles mencione ou mostre a África do Sul em um mapa da África, menos de 10\% aponta que os holandeses fundaram a colônia. Em vez disso, ela é descrita como uma escala para exploradores ou comerciantes a caminho da Indonésia. Apenas 13,7\% mencionam Elmina ou Guiné, outros nomes para a Costa do Ouro holandesa (atual Gana). E o apartheid sul-africano está completamente desassociado dos holandeses. Os 
livros didáticos colocam as organizações ocidentais de ajuda humanitária, como ONU, Unicef e a ONG holandesa Novib, que aparecem em 14,4\% dos livros, como necessárias para resolver os problemas descritos anteriormente. Além disso, retratam os holandeses como particularmente dedicados à ajuda humanitária. A ONG holandesa Novib "ajuda esses países pobres, construindo hospitais e escolas, ou apoiando agricultores com a instalação de poços para abastecimento de água" (Vorst; Weeber, 2004, p. 106). Outro livro afirma, "voluntários holandeses foram enviados para levar seu conhecimento à população local" (Panday et al., 2001, p. 69).

Imigrantes

Menos de um quinto $(18,7 \%)$ de todos os livros didáticos menciona imigrantes. Os imigrantes mais citados são, em ordem decrescente: surinameses, indonésios, trabalhadores convidados (guest workers) (geralmente turcos, marroquinos, italianos e espanhóis), refugiados fugidos da Ásia, África, América do Sul e da ex-lugoslávia, judeus e outros europeus. A maioria dos livros apresenta os grupos de imigrantes e os anos de chegada, sem explicar sua emigração. Quando há explicação, elas referem que os imigrantes deixaram seus países para fugir da violência, encontrar trabalho, evitar a perseguição religiosa, escapar da pobreza, procurar um "futuro melhor" ou "vida melhor" ou para buscar educação (Berserik, 2005; den Otter; Maters, 2001; Kratsborn et al. 2007; Sonderen et al., 2006). Com exceção de uma coleção de livros, nos demais os imigrantes são compartimentados em seus grupos, separados do restante da sociedade holandesa. 
Sociologias, Porto Alegre, ano 17, no 40, set/dez 2015, p. 212-254

Tabela 5. Variáveis relacionadas à imigração

$\%$

Grupos de imigrantes

$\begin{array}{lc}\text { Indonésios } & 50 \\ \text { Surinameses } & 65.8 \\ \text { Antilhanos } & 18.4 \\ \text { Turcos } & 57.9 \\ \text { Marroquinos } & 57.9 \\ \text { Italianos } & 28.9 \\ \text { Espanhóis } & 26.3 \\ \text { Judeus } & 15.8 \\ \text { Africanos } & 28.9 \\ \text { Asiáticos } & 34.2 \\ \text { lugoslavos } & 26.3 \\ \text { Sul-americanos } & 15.8 \\ \text { Outros europeus } & 42.1 \\ \text { Trabalhadores convidados } & 47.4 \\ \text { Refugiados } & 60.5\end{array}$

Motivos para deixar o país

Religião

36.8

Trabalho

42.1

Educação

13.2

Crenças políticas

15.8

Violência

44.7

Futuro melhor

15.8

Pobreza

18.4 
continuação

\begin{tabular}{lll}
\hline & & $\%$ \\
\hline Características & & \\
& Diferenças culturais & 44.7 \\
& Islã & 15.8 \\
& Pobreza & 31.6 \\
& Urbanos & 15.8 \\
Tolerância? & & \\
& Multicultural & 28.9 \\
& Colorido & 7.9 \\
& Multicultural + Colorido & 34.2 \\
& Allochtoon & 23.7 \\
& Discriminação nos PB & 42.1 \\
& Benevolência & 18.4 \\
Números & Problemas & 21.1 \\
\hline
\end{tabular}

Quase metade dos livros destaca as diferenças e a condição de estrangeiros dos imigrantes, independentemente do seu tempo de residência na Holanda. Um livro afirma que "há muitas semelhanças entre crianças turcas, marroquinas, surinameses e holandesas... Mas há também grandes diferenças" (Fenger; Siemensma, 2004, p. 75). Com base nessas diferenças, um terço $(34,2 \%)$ dos livros considera os Países Baixos uma sociedade multicultural e/ou "colorida".

Enquanto as vozes de imigrantes raramente aparecem (em 34\% dos livros, e apenas para destacar sua felicidade por estar no país), dá-se destaque à perspectiva dos holandeses brancos, que se presume 
não serem imigrantes. Isso, muitas vezes, realiza-se por meio de termos considerados ofensivos para muitos imigrantes (como allochtonen, buitenlanders e vreemdelingen), com o uso de allochtoon por quase um quarto $(23,7 \%)$ dos livros. Esses também apresentam uma perspectiva holandesa xenofóbica, sugerindo a presença de imigrantes demais ou que esses deveriam esforçar-se mais para assimilar-se. Ao mesmo tempo, fazem referência à benevolência holandesa (que aparece em 18\% dos livros) ao aceitar imigrantes (Baaijens; Klinken, 1997; Fenger; Siemensma, 2004; Kratsborn et al., 2007). Embora os imigrantes vivenciem "problemas" (em 21\% dos livros), o racismo, o preconceito e a discriminação não aparecem como causa.

\section{Discussão}

Este trabalho reúne estudos críticos internacionais e holandeses acerca do papel da Holanda no comércio e escravização de africanos, na ajuda econômica à África, e na história e integração socioeconômica de imigrantes no país, bem como aquela que examina a presença desses fenômenos nos livros didáticos, a fim de oferecer uma síntese e uma análise de suas representações nos livros de história usados no ensino primário holandês. Os livros didáticos exibem uma certa "afasia" holandesa, isto é, uma incapacidade de discutir e integrar o passado colonial em sua narrativa nacional (Bijl, 2002), dissociando sua ação colonialista em todo o mundo, particularmente na África, das condições socioeconômicas contemporâneas dos holandeses não europeus no país e no exterior, e colocando os holandeses brancos como superiores em ambos os contextos. Essas representações facultam entendimentos cruciais a respeito da narrativa histórica nacional. Os livros didáticos colocam a nação holandesa no topo da hierarquia racial global ao enfatizar discursivamente a 
alteridade de outras nações e povos para reafirmar a concepção geral da supremacia branca na forma da modernidade e da civilização. A história especificamente holandesa da escravidão, juntamente com as políticas atuais voltadas aos imigrantes e as políticas de ajuda internacional, resulta em livros didáticos que indicam um "fardo holandês", o qual se alinha com as ideologias raciais dominantes no país.

Os livros didáticos encobrem e distorcem o papel desempenhado pela Holanda na escravização de africanos, justificam sua história de colonialismo, exploração, opressão e genocídio com base na busca de rendas e mão-de-obra, e promovem o privilégio epistêmico eurocêntrico, dissociando o colonialismo e a exploração capitalista de africanos da presença holandesa em suas colônias. Tal narrativa rompe as conexões históricas entre a opressão dos africanos escravizados e a ascensão da Holanda como um poder econômico global, as ideologias raciais, e as desigualdades socioeconômicas vivenciadas por afro-holandeses em todo o reino holandês, atual e antigo. A banalização da escravidão provavelmente contribui para a longeva resistência da sociedade holandesa ao uso dos termos "raça" ou "racismo institucional" (Essed; Nimako, 2006; Essed; Trienekens, 2008; Hondius, 2013). Da mesma forma, essa narrativa perpetua a duradoura (e, para muitos, ultrapassada) tradição do Zwarte Piet, o ajudante, de cara pintada de negro, de Sinterklaas [personagem holandês inspirado em São Nicolau], que pode ser visto por toda a Holanda durante a época do Natal, e as críticas amargas dirigidas pelos holandeses brancos aos oponentes da manutenção do personagem Zwarte Piet (Helsloot, 2012; Hondius, 2014).

As representações da África revelam uma construção nitidamente eurocêntrica arraigada em concepções de modernidade desenvolvidas durante a investigação e exploração colonial, que retratavam a África e os africanos como um grupo essencializado, homogeneizado, ao qual 
faltariam racionalidade, civilização, modernidade e, posteriormente, industrialização e capitalismo em comparação aos europeus (Grosfoguel, 2011; Hesse, 2007). Os livros didáticos obscurecem o papel das intervenções ocidentais no agravamento de problemas, em especial os da pobreza e do "subdesenvolvimento", sugerindo às crianças, em vez disso, que as nações africanas independentes são incompetentes, incivilizadas e ainda pré-modernas, incapazes de criar sistemas econômicos, educacionais ou de saúde que funcionem. Livros didáticos que racializam os holandeses (brancos) como humanitários, ao invés de colonialistas históricos, promovem a superioridade da Holanda em relação a outros países, sem criticar os impactos desse auxílio sobre as populações e comunidades (Bond, 2000; Jordan; Tuijl, 2007). Consequentemente, esses livros assumem hoje um papel central na construção continuada da África em contraposição à Europa capitalista, de maneira parecida às doutrinas governamentais e religiosas em séculos anteriores. Essas diferenças culturais constituem o fundamento dos discursos neoliberais internacionais que perpetuam relações históricas colonialistas e contribuem para uma hierarquia racial global (Bonilla-Silva, 2000; Goldberg, 2009).

Descrever os imigrantes como vindos de nações repletas de violência, perseguição religiosa, pobreza e onde faltam várias liberdades coloca a Holanda como uma nação superior, e assemelha-se à produção intelectual recente sobre imigração que destaca os problemas trazidos pelos imigrantes e perpetuados na Holanda, dificultando sua integração socioeconômica na sociedade holandesa (Essed; Nimako, 2006; Nimako, 2012). Nega-se o racismo na Holanda e a discriminação é minimizada, como algo casual e individual, ao invés de figurar nos livros didáticos como uma barreira institucional que impede o êxito socioeconômico ou o bem-estar psicológico duradouros dos imigrantes. Ao enfatizarem-se as diferenças culturais dos imigrantes, independentemente de assimilação cultural, eles 
seguem sendo vistos como "outsiders" que drenam um país benevolente de seus recursos financeiros vitais. Essa omissão e delimitação de fronteiras é sintomática da europeização racial, retratando a Europa como um continente homogêneo, que generosamente permite a entrada de recém-chegados, mas ao mesmo tempo teme a possível destruição da homogeneidade cultural nacional (Goldberg, 2009; Grosfoguel, 2011).

\section{Conclusão}

Nas suas discussões de escravidão, África e imigrantes, os livros didáticos holandeses promovem uma narrativa mestra eurocêntrica que reflete o neoliberalismo racial no contexto particular da história do colonialismo holandês. Debates atuais sobre a presença de europeus não brancos na Holanda, especialmente muçulmanos e afro-holandeses de origem colonial, e sobre o legado de séculos de colonialismo holandês revelam grandes controvérsias a respeito da narrativa nacional e da cidadania. Esses livros têm implicações importantes sobre - e provavelmente contribuem com - a aversão aos imigrantes que persiste hoje na Holanda. Dado o amplamente documentado papel dos livros didáticos na formação das concepções das crianças sobre esses fenômenos, os achados desta pesquisa, especialmente aqueles que indicam a perpetuação de representações que salientam a alteridade das pessoas de origem não holandesa dentro e fora do país, sugerem que esses livros provavelmente formaram a visão geral de muitos dos holandeses brancos que apoiam ou votam a favor das políticas internas excludentes e internacionais paternalistas.

No que concerne às questões nacionais, ao ignorar a perspectiva dos imigrantes, esses livros perpetuam epistemologias raciais brancas e a colonialidade do poder educacional, em que os imigrantes constituem perpétuos "outsiders" dentro da nação holandesa, o que provavelmen- 
te contribui para a hierarquia socioeconômica racial e a xenofobia hoje existentes na Holanda. Da perspectiva internacional, esses livros não só posicionam a Europa, e particularmente os holandeses, como superiores em termos culturais, intelectuais, tecnológicos e civilizatórios, como também colocam a África e os imigrantes que vivem na Holanda como dependentes dos holandeses. Isso facilita a transmissão de uma narrativa nacional semelhante à do histórico "fardo do homem branco", que postula a responsabilidade dos brancos ocidentais de introduzirem os povos não brancos à era moderna, por serem incivilizados e carentes de tecnologia e de modernidade. Na Holanda, esta narrativa sugere que os holandeses são generosos demais, tanto para com os imigrantes no país quanto para com os habitantes da África, construídos como necessitados de sua ajuda.

Em vista do reconhecido papel da educação formal em formar as concepções que as crianças têm de seu país, da realidade e das identidades (Marmer et al., 2010), esses livros didáticos revelam os fundamentos da ideologia racial neoliberal absorvidos pelos holandeses adultos de hoje, os quais a atual geração de crianças do país aprenderá a valorizar. Tanto pela exclusão total como pela ênfase nas diferenças culturais que separam "nós" de "eles", os livros didáticos da Holanda sustentam as ideologias racializantes do nacionalismo, do colonialismo e da supremacia branca e, provavelmente, contribuem para a hierarquia racial do país. Ao ler esses livros, estudantes brancos holandeses aprendem como sua sociedade concebe os imigrantes de todo o mundo e provavelmente têm dificuldades para considerar os não brancos como iguais.

Ao privar os alunos de todas as origens étnicas e raciais, do conhecimento correto sobre a história de seu país, os livros didáticos terão consequências concretas para a sociedade holandesa. Eles podem limitar a capacidade dos holandeses brancos de reconhecerem ou enfrentarem o racismo institucional hoje existente na sociedade, o qual contribui para 
a persistente exclusão social, econômica e política de várias gerações de imigrantes. O acesso limitado ao conhecimento preciso sobre raça, racismo e imigrantes seguirá contribuindo para ideias xenofóbicas e anti-imigração, e para a relutância em abordar as persistentes consequências de séculos de intervenção colonialista global que até hoje mantém cidadãos holandeses não brancos como eternos forasteiros em sua própria nação. Esses resultados são relevantes para países de todo o continente europeu com populações crescentes, e cada vez mais mobilizadas, de imigrantes e que exibem formas semelhantes de sentimentos, discursos populares e políticos, e políticas públicas anti-imigração/afro-fóbicos.

Como muitas ex-colônias continuam usando livros didáticos desenvolvidos em suas antigas metrópoles coloniais (como é o caso em Curaçau e no Suriname), essa pesquisa também tem implicações importantes para a ex-colônias na África, no Caribe e na América do Sul. Nesses países, esses livros didáticos perpetuam sentimentos de superioridade europeia e podem inibir movimentos nacionalistas e de independência anti-europeias/ocidentais/capitalistas entre gerações de crianças que leem livros impregnados de neoliberalismo racial, os quais desconectam sua realidade cotidiana colonizada dos séculos de exploração europeia. Da mesma forma, o fato de esses livros justificarem a presença de organizações humanitárias ocidentais, minimizarem paternalisticamente a importância dos movimentos de independência anticoloniais e reificarem concepções de afrodescendentes como essencialmente pobres, violentos e anti-intelectuais, provavelmente contribui para promover o neocolonialismo de interesses corporativos baseados nas antigas metrópoles coloniais que substituiu o colonialismo estatal em grande parte do mundo não europeu. 
Melissa Weiner é Professora Associada de Sociologia da College of the Holy Cross, Worcester, Massachussets (EUA) e pesquisadora do Institute on Race and Poverty (Faculdade de Direito da Universidade de Minnesota). $\triangle$ mfweiner@holycross.edu

\section{Agradecimentos}

A autora é profundamente grata à Spencer Education Foundation por financiar esta pesquisa (Concessão no 201100032) e aos feedbacks de Antonio Carmona Báez, Kwame Nimako, Stephen Small, Philomena Essed, Eric Mielants, Jeffrey Dixon, Artwell Cain, Marta Araújo e Donna Driver-Zwartkruis na elaboração dos vários manuscritos nos quais este artigo se baseia.

\section{Referências}

1. ALVERMANN, D.E.; COMMEYRAS, M. Messages that high school world history textbooks convey: Challenges for multicultural literacy. Social Studies, v. 85, n. 6, p. 268-274, 1994.

2. APPLE, M.W.; CHRISTIAN-SMITH, L.K. The politics of the textbook. In: APPLE M.W. et al (Eds.) The politics of the textbook. New York: Routledge. p. 1-21.

3. ARAÚJO, M.; MAESO, S.R. History Textbooks, Racism and the Critique of Eurocentrism: Beyond rectification or compensation. Ethnic and Racial Studies, v. 35, n. 7, p. 1266-1286, 2012a

4. ARAÚJO, M.; MAESO, S.R. Slavery and racism as the "wrongs" of (European) history: Reflections from a study on Portuguese textbooks." IN: HAMILTON D. et al (Eds.) Slavery, Memory and Identity. London: Pickering \& Chatto, 2012b. p. 151-166.

5. BAAIJENS, P.; LEUNIS, D.v.K. Er is geschied, Leerlingboek Deel 3. Heerenveen: Groen Educatief, 1996.

6. BERSERIK, T. Korte klapper geschiedenis. Gronigen: Scala Leuker Leren, 2005.

7. BEBBINGTON, A. Donor-NGO relations and representations of livelihood in nongovernmental aid chains. World Development, v. 33, n. 6, p. 937-950, 2005. 
Sociologias, Porto Alegre, ano 17, no 40, set/dez 2015, p. 212-254

8. BIJL, P. Colonial memory and forgetting in The Netherlands and Indonesia. Journal of Genocide Research, v. 14, n. 3-4, p. 441-461, 2012.

9. BINDER, A.J. Contentious Curricula: Afrocentrism and creationism in American public schools. Princeton, NJ: Princeton University Press, 2002.

10. BOIVIN, B.; TORREMAN, K. Toegang geschiedenis 3. Groningen: WoltersNoordhoff, 1995

11. BOND, M. The backlash against NGOs. Prospect, April, 2000.

12. BONILLA-SILVA, E. "This is a white country": The racial ideology of the western nations of the world-system. Sociological Inquiry, v. 70, n. 2, p. 188-214, 2000.

13. BROECK, S. Traveling memory: The middle passage in German representation. The Massachusetts Review, v. 44, n. 1/2, p. 157-166, 2003.

14. BROWN, A.L.; BROWN, K.K.D. Strange fruit indeed: Interrogating contemporary textbook representations of racial violence toward African Americans. Teachers College Record, v. 112, n. 1, p. 31-67, 2010.

15. BRUG, E. Groei: Ontmoetingen met het verleden, Blauw/Violet. Utrecht, NL: Kok Educatief, 1991.

16. BUIJTENDIJK, C.J.; KUPERUS, W.; SEIP, C.J. Geschiedenis in onderwerp en opdracht, Leerlingboek 5. Amsterdam: Meulenhoff, 1986.

17. BRENNINKMEYER, K.; HOUDT, P.; DER LEEUW-ROORD, J. Wereldbeelden, Deel 2. Meppel: Edu'Actief, 1995.

18. BRUIN, R. de. Een Zee van Tijd, Lesboek 8. Tilburg: Zwijsen Educatief, 2003a.

19. BRUIN, R. de. Een Zee van Tijd, Lesboek 6. Tilburg: Zwijsen Educatief, 2003b.

20. BRUIN, R. de. Een Zee van Tijd, Leerlingboek F, 6th Ed. Tilburg: Zwijsen, 2001.

21. COLE, M. "Rule Britannia" and the new American empire: A Marxist analysis of the teaching of imperialism, actual and potential, in British school curriculum. Policy Futures in Education, v. 2, n. 3\&4, p. 523-538, 2004.

22. DERKSEN, H.; VERHALLEN, P. Reinventing international NGOs: A view from the Dutch co-financing system. In: BEBBINGTON, A. et al (Eds.). Can NGOs make a difference? The challenge of development alternatives. London: Zed Books, 2007. p 221-239. 
23. DEVEAU, J.M. Towards the pedagogy of the history of the slaver trade. IN: DIÈNE D. (Ed.). From Chains to Bonds: The Slave Trade Revisited. Oxford \& Paris: UNESCO \& Berghahn Books, 2001. p. 397-415.

24. DIJK, T.A. Elite discourse and racism. Newbury Park, CA: Sage, 1993.

25. DOWNING, J. The Media Machine. London: Pluto Press, 1980.

26. DRESCHER, S. The long goodbye: Dutch capitalism and antislavery in comparative perspective. American Historical Review, v. 99, n. 1, p. 44-69, 1994.

27. DUINEN, G. Vroeger was het anders, Deel 4. Zutphen, Thieme, 1983.

28. ENGBERSEN, G.; LEUN, J. The social construction of illegality and criminality. European Journal on Criminal Policy and Research, v. 9, n. 1, p. 51-70, 2001.

29. ESSED, P.; HOVING, I. Dutch Racism. Amsterdam, NL: Rodopi, 2014.

30. ESSED, P.; NIMAKO, K. Designs and (Co)incidents: Cultures of scholarship and public policy on immigrants/minorities in The Netherlands. International Journal of Comparative Sociology, v. 47, n. 3-4, p. 281-312, 2006.

31. ESSED, P.; TRIENEKENS, S. "Who wants to feel white?" Race, Dutch culture, and contested identities. Ethnic and Racial Studies, v. 31, n. 1, p. 52-72, 2008.

32. FENGER, P.; SIEMENSMA, F.J. Tijdstip, Werkboek 7. Groningen: WoltersNoordhoff, 2005.

33. FENGER, P.; SIEMENSMA, F.J. Tijdstip, Leerlingboek 7. Groningen: WoltersNoordhoff, 2004

34. FEREDAY, J.; MUIR-COCHRANE, E. Demonstrating rigor using thematic analysis: A hybrid approach of inductive and deductive coding and theme development. International Journal of Qualitative Methods, v. 5, n. 1, p. 80-92, 2006

35. FITZGERALD, F. America revised: History schoolbooks in the twentieth century. New York: Vintage, 1979.

36. FOSTER, S.J. The struggle for American identity: Treatment of ethnic groups in United States history textbooks. History of Education, v. 28, n. 3, p. 251-278, 1999.

37. FRANKENBERG, R. The mirage of unmarked whiteness. IN: Rasmussen B.B. et al (Eds.). The making and unmaking of whiteness, Durham, NC: Duke University Press, 2001. p. 72-96

38. FREDRICKSON, G.M. White supremacy: A comparative study in American and South African history. Oxford: Oxford University Press, 1981. 
39. FRIJHOFF, W. The Relevance of Dutch history, or: Much in little: Reflections on the practice of history in The Netherlands. Low Countries Historical Review, v. 125, n. 2-3, p. 7-44, 2010.

40. GHORASHI, H. National identity and the sense of (non-)belonging: Iranians in the United States and The Netherlands. In: ALGHASI, S. et al (Eds.). Paradoxes of Cultural Recognition: Perspectives from Northern Europe. Farnham, UK: Palgrave, 2009. p. 75-88.

41. GIROUX, H. Racial politics and the pedagogy of whiteness. IN: HILL M (Ed.). Whiteness: A critical reader. New York: New York University Press, 1997. p. 294315.

42. GIROUX, H.A.; MCLAREN, P. Critical education, the state and cultural struggle. Albany: State University of New York Press, 1989.

43. GOLDBERG, D.T. The Threat of Race: Reflections on Racial Neoliberalism. Hoboken, NJ: Wiley-Blackwell, 2009.

44. GORDY, L.L.; PRITCHARD, A.A.M. Redirecting our voyage through history: A content analysis of social studies textbooks. Urban Education, v. 30, n. 2, p. 195-218, 1995.

45. GORIS, M. et al. Brandaan: Geschiedienis, Lesboek 6. 's-Hertogenbosch: Malmberg, 2008.

46. GROSFOGUEL, R. Decolonising post-colonial studies and paradigms of political economy: Transmodernity, decolonial thinking, and global coloniality. Transmodernity, v. 1, n. 12011 http://escholarship.org/uc/item/21k6t3fq.

47. HEATH, A.F.; ROTHON, C.; KILPI, E. The second generation in Western Europe: Education, unemployment, and occupational attainment. Annual Review of Sociology, v. 34, p. 211-235, 2008.

48. HELSLOOT, J. Zwarte Piet and cultural aphasia in The Netherlands. Quotidian: Dutch Journal for the Study of Everyday Life, v. 3, n. 1, 2012. http://www. quotidian.nl/vol03/nr01/a01

49. HESSE, B. Racialized modernity: An analytics of white mythologies. Ethnic and Racial Studies, v. 30, n. 4, p. 643-663, 2007.

50. HIRA, S. Decolonizing the mind: The case of The Netherlands. Human Architecture, v. 10, n. 1, p. 53-68, 2012.

51. HOEBINK, P. The humanitarianisation of the foreign aid programme in The Netherlands. European Journal of Development Research, v. 11, n. 1, p. 176202, 1999. 
52. HONDIUS, D. Black Dutch voices: Reports from a country that leaves racism unchallenged. IN: ESSED P.; HOVING I. (Eds.). Dutch Racism. Amsterdam, NL: Rodopi, 2014. p 273-293.

53. HONDIUS, D. Access to The Netherlands of enslaved and free black Africans: Exploring legal and social historical practices in the sixteenth-nineteenth centuries. Slavery \& Abolition, v. 32, n. 3, p. 377-395, 2011.

54. HORTON, J.; KARDUX J.C. Slavery and public memory in the United States and The Netherlands. New York Journal of American History, v. 46, n. 2, p. 3552, 2005.

55. JANSSEN, K.E.; MATERS, A.; VONK, M. Varia: Geschiedenis Tijdvak 6 t/m 10, Groep 7. Amersfoort: Thieme Meulenhoff, 2010.

56. JORDAN, L.; TUIJL, P. NGO accountability: Politics, principles and innovations. London: Earthscan, 2007.

57. KRATSBORN, W.M.L.; VERSCHUREN, B.; VERMEER, H. De Trek: Groep 6, Lesboek Deel 4. Tilburg: Zwijsen, 2007.

58. LOEWEN, J. Lies my teacher told me: Everything your American history textbook got wrong. New York: Touchstone, 2007.

59. LYNDON, D. Integrating Black British history into the national curriculum. Teaching History, v. 122, p. 37-43, 2006.

60. MALDONADO-TORRES, N. On the coloniality of being: Contributions to the development of a concept. Cultural Studies, v. 21, n. 2-3, p. 240-270, 2007.

61. MANZO, K. An extension of colonialism? Development education, images and the media. Development Education Journal, v. 12, n. 2, p. 9-12, 2006.

62. MARINO, M.P. High school world history textbooks: An analysis of content focus and chronological approaches. The History Teacher v. 44, n. 3, p. 421-446, 2011.

63. MAGUBANE, Z. Bringing empire home: Race, class, and gender in Britain and colonial South Africa. Chicago, IL: University of Chicago Press, 2004.

64. MARMER, E. et al. Racism and the image of Africa in German schools and textbooks. International Journal of Diversity in Organisations, Communities and Nations, v. 10, n. 5, p. 1-12, 2010.

65. MIGNOLO, W. Local histories/global designs: Essays on the coloniality of power, subaltern knowledges, and border thinking. Princeton, NJ: Princeton University Press, 2000.

66. MOK, I. Anti-Racisme in Schoolboeken. Amsterdam: University of Amsterdam, Program of Discourse Studies, 1990. 
67. MOREAU, J. School book nation: Conflicts over American history textbooks from the Civil War to the present. Ann Arbor, MI: University of Michigan Press, 2003.

68. MYERS, G.A. Introductory human geography textbook representations of Africa. Professional Geographer, v. 53, n. 4, p. 522-532, 2001.

69. NIMAKO, K. Reorienting the World: With or Without Africa? Working Paper No. 5, University of South Australia, International Center for Muslim and NonMuslim Understanding, 2011.

70. NIMAKO, K. About them, but without them: Race and ethnic relations studies in Dutch universities. Human Architecture, v. 10, n. 1, p. 45-52, 2012.

71. NIMAKO, K.; SMALL, S. Collective memory of slavery in Great Britain and The Netherlands. In: SCHALKWIJK, S.; SMALL, S. (Eds.). New perspectives on slavery and colonialism in the Caribbean. The Hague \& Amsterdam: Amrit \& NiNsee, 2012. p. 92-115.

72. NIMAKO, K.; WILLEMSEN, G. The Dutch Atlantic: Slavery, Abolition, and Emancipation. London: Pluto Press, 2011.

73. OGDEN, N.; PERKINS, C.; DONAHUE, D.D.M. Not a peculiar institution: Challenging students' assumptions about slavery in U.S. History. The History Teacher, v. 41, n. 4, p. 469-488, 2008.

74. OTTER, J. den; MATERS, A. Bij de Tijd, Leerlingboek 4. Den Bosch: Malmberg, 2001

75. OURS, J.C.; VEENMAN, J. The educational attainment of second-generation immigrants in The Netherlands. Journal of Population Economics, v. 16, n. 4, p. 739-753, 2003.

76. PANDAY, R.S.; KOUWENBERG, B. De Grote Reis, Zoekboek 8. Den Bosch: Malmberg, 2001.

77. PANDAY, R.S.; KOUWENBERG, B.; VERHOEVEN, C.M.S. De Grote Reis, Lesboek 8B. 's-Hertogenbosch: Malmberg, 2001.

78. PANDAY, R.S.; KOUWENBERG, B.; ENGELEN, H. De Grote Reis, Lesboek 7B. 's-Hertogenbosch: Malmberg, 2000.

79. PESCOSOLIDO, B.A.; GRAUERHOLZ, E.; MILKIE, M.A. Culture and conflict: The portrayal of Blacks in U.S. children's picture books through the mid- and latetwentieth century. American Sociological Review, v. 62, n. 3, p. 443-464, 1997.

80. PINAR, W.F. Notes on understanding curriculum as a racial text. In: MCCARTHY, C.; CHRICHLOW, W. (Eds.). Race, Identity and Representation in Education. New York: Routledge, 1993. p. 60-70. 
81. POPKE, J. The Politics of the Mirror: On geography and Afro-pessimism. African Geographical Review, v. 21, n. 1, p. 5-27, 2001.

82. QUIJANO, A. Coloniality of Power, Eurocentrism, and Latin America. Nepantla, v. 1, p. 533-580, 2000.

83. REENEN, J. De grote geschiedenis van een klein land, Deel 1. Utrecht: De Banier, 1998.

84. SEFA DEI, G.J. Teaching Africa: Towards a transgressive pedagogy. Dordrecht, NL: Springer, 2010.

85. SIVANANDAN, A. A Different Hunger. London: Pluto Press, 1982.

86. SMALL, S. Foreward. In: NIMAKO, K.; WILLEMSEN, G. The Dutch Atlantic: Slavery, abolition, and emancipation. London: Pluto Pres, 2011. p. xii-xxi.

87. SNEL, E., BOOM, D.B.; ENGBERSEN, G. Migration and migration policies in The Netherlands. Dutch SOPEMI Report. Rotterdam: Rotterdam Institute of Social Research, Erasmus University, 2005.

88. SNIDERMAN, P.M.; HAGENDOORN, L. When ways of life collide: Multiculturalism and its discontents in The Netherlands. Princeton, NJ: Princeton University Press, 2009.

89. SONDEREN, J. et al. Wijzer door de Tijd: Leerlingboek 8. Groningen, NL: Wolters-Noordhoff, 2006.

90. SUNIER, T. Teaching the nation: Religious and ethnic diversity at state schools in Britain and The Netherlands. Teachers College Record, v. 111, n. 6, p. 15551581, 2009.

91. SWARTZ, E. Emancipatory narratives: Rewriting the master script in the school curriculum. Journal of Negro Education, v. 61, n. 3, p. 341-355, 1992.

92. TYACK, D. Monuments between covers: The politics of textbooks. American Behavioral Scientist, v. 42, n. 6, p. 922-932, 1999.

93. VASTA, E. From ethnic minorities to ethnic majority policy: Multiculturalism and the shift to assimilationism in The Netherlands. Ethnic and Racial Studies, v. 30, n. 5, p. 713-740, 2007.

94. VENEMA B. Op zoek naar vroeger, Deel 2. Groningen: Dijkstra, 1985.

95. VISSER-van de BRINK, T.; HUIJZER, M.; SIEMENSMA, F.J. Wijzer door de tijd, Leerlingboek 7. Groningen: Wolters-Noordhoff, 2006.

96. VLIS, W. Spoorzoeken in de tijd, Deel 3. Groningen: Wolters-Noordhoff, 1986. 
97. VORST, M.; WEEBER, F.J. Tijdstip, Leerlingboek 8. Groningen: WoltersNoordhoff, 2004.

98. WAGENAAR, H. et al. Bij de tijd, Leerlingboek Groep 8. Den Bosch: Malmberg, 2004.

99. WALLERSTEIN, I. The modern world-System II: Mercantilism and the consolidation of the European world economy, 1600-1750. Bingley, UK: Emerald Group Publishing, 1980.

100. WALLERSTEIN, I. The modern world system I: Capitalist agriculture and the origins of the European world-economy in the sixteenth century. New York: Academic Press, 1974.

101. WEINER, M.F. (E)Racing slavery: Racial neoliberalism, social forgetting and scientific colonialism in Dutch primary school history textbooks. DuBois Review, v. 11, n. 2, 2014a.

102. WEINER, M.F. The ideologically colonized metropole: Dutch racism and racist denial. Sociology Compass v. 8, n. 6, p. 731-744, 2014 b.

103. WEINER, M.F. Power, protest and the public schools: Jewish and African American struggles in New York City. New Brunswick, NJ: Rutgers University Press, 2010.

104. WILLINSKY, J. Learning to divide the world: Education at empire's end. Minneapolis: University of Minnesota Press, 1998.

105. WILSON, A.H. Teaching about Africa: A review of middle/secondary textbooks and supplemental materials. Social Studies, v. 86, n. 6, p. 253-259, 1995. 106. ZIMMERMAN, J. Whose America? Culture wars in the public schools. Cambridge, MA: Harvard University Press, 2002.

107. ZUNDER, A. Herstelbetalingen: De 'wiedergutmachung' voor de schade die Suriname en haar bevolking hebben geleden onder het Nederlands kolonialisme. The Hague, NL: Amrit, 2010.

Recebido: 28/01/2015

Aceite final: 02/06/2015 